\title{
HOXA10 is Expressed in Response to Sex Steroids at the Time of Implantation in the Human Endometrium
}

\author{
Hugh S. Taylor, ${ }^{\star}$ Aydin Arici, ${ }^{*}$ David Olive, ${ }^{\star}$ and Peter Igarashi ${ }^{\ddagger}$ \\ *Division of Reproductive Endocrinology, Department of Obstetrics and Gynecology, Yale University School of Medicine, New Haven, \\ Connecticut 06520; and $\doteqdot$ Section of Nephrology, Department of Internal Medicine, Yale University School of Medicine, New Haven, \\ Connecticut 06520
}

\begin{abstract}
Hox genes are well-known transcriptional regulators that play an essential role in directing embryonic development. Mice that are homozygous for a targeted disruption of the Hoxa10 gene exhibit uterine factor infertility. We have recently demonstrated that $\mathrm{HOXA10}$ is expressed in the adult human uterus. To examine expression of HOXA10 during the menstrual cycle, Northern blot analysis and in situ hybridization were performed. Expression of HOXA10 dramatically increased during the midsecretory phase of the menstrual cycle, corresponding to the time of implantation and increase in circulating progesterone. Expression of HOXA10 in cultured endometrial cells was stimulated by estrogen or progesterone. Stimulation of HOXA10 by progesterone was concentration-dependent within the physiologic range, and the effect of estrogen was inhibited by cycloheximide. These results identify sex steroids as novel regulators of $H O X$ gene expression. $H O X A 10$ may have an important function in regulating endometrial development during the menstrual cycle and in establishing conditions necessary for implantation in the human. (J. Clin. Invest. 1998. 101:1379-1384.) Key words: genes • homeobox • menstrual cycle $\bullet$ steroids $\bullet$ reproduction $\bullet$ pregnancy
\end{abstract}

\section{Introduction}

Uterine endometrium is one of the most dynamic tissues in the human body, undergoing dramatic developmental changes during each monthly menstrual cycle. Disorders of endometrial development lead to infertility, dysfunctional bleeding, endometriosis, and neoplasia. The molecular mechanisms that direct the ordered proliferation, differentiation, and cell death associated with the normal menstrual cycle are still poorly understood. Besides estrogen and progesterone receptors, no well-characterized transcription factors have been demonstrated to regulate gene expression in the developing endo-

Address correspondence to Hugh S. Taylor, Division of Reproductive Endocrinology, Department of Obstetrics and Gynecology, Yale University School of Medicine, 333 Cedar Street, New Haven, CT 06520. Phone: 203-785-6635; FAX: 203-785-7134; E-mail: hugh.taylor@ yale.edu

Received for publication 27 June 1997 and accepted in revised form 21 January 1998.

J. Clin. Invest.

(C) The American Society for Clinical Investigation, Inc. 0021-9738/98/04/1379/06 \$2.00

Volume 101, Number 7, April 1998, 1379-1384

http://www.jci.org metrium. Hox genes are good candidates for regulating differentiation of the endometrium. Hox genes are transcriptional regulators that play essential roles in directing embryonic development (1). Hox genes are the vertebrate homologs of the Drosophila homeotic genes that determine the identity of specific body segments $(1,2)$. Recently, expression of Hox genes has been demonstrated in the developing reproductive system of the mouse $(4,5)$. Specifically, Hoxa10 has been shown to be expressed in the uterus of the fetal mouse (6). We have recently observed that expression of Hoxa cluster genes persists in the female reproductive tract, and that $H O X A 10$ is expressed in the adult human endometrium (7).

In the mouse, Hoxal0 expression is essential for fertility. Mice carrying a targeted disruption of the Hoxal0 gene exhibit uterine factor infertility. Females ovulate normally, but do not support the preimplantation embryo or allow implantation. Mutant embryos are viable when placed in a surrogate (6). Taken together, these studies suggest that Hoxal0 is required for endometrial differentiation and for establishing the conditions required for implantation. We postulated that $H O X A 10$ may have a similar function in the human. We observed that expression of $H O X A 10$ in the human uterus is menstrual cycle stage-dependent, and identified sex steroids as novel regulators of $H O X$ gene expression.

\section{Methods}

Tissue collection. Endometrium was collected from normal cycling women by endometrial biopsy under an approved Human Investigations Committee protocol. Half of the tissue was immediately frozen in liquid nitrogen and stored at $-72^{\circ} \mathrm{C}$. The other half of the tissue sample was fixed in formalin, embedded in paraffin, sectioned, and stained with hematoxylin and eosin. Menstrual cycle dating was determined by menstrual history and confirmed by histological examination using the criteria of Noyes et al. (8).

Northern blot analysis. Tissues or cultured cells were homogenized in $4 \mathrm{M}$ guanidinium thiocyanate, $25 \mathrm{mM}$ sodium citrate $(\mathrm{pH}$ 7.0), $0.5 \%$ sarkosyl, and $0.1 \mathrm{M}$ 2-mercaptoethanol. Total RNA was size-fractionated on a $1 \%$ agarose $/ 0.66 \mathrm{M}$ formaldehyde gel, and transferred to nylon membranes. Membranes were hybridized with a ${ }^{32} \mathrm{P}$-labeled riboprobe as described below. Hybridization was performed overnight at $60^{\circ} \mathrm{C}$ in $50 \%$ formamide, $1 \times \mathrm{SSC}, 5 \times$ Denhardt's reagent, $0.2 \%$ tRNA, and ${ }^{32} \mathrm{P}$-labeled riboprobe at $2 \times 10^{6} \mathrm{cpm} / \mathrm{ml}$. The filter was washed twice at $68^{\circ} \mathrm{C}$ for $30 \mathrm{~min}$ in $0.1 \times \mathrm{SSC}$ and $0.1 \%$ SDS. X-Omat AR film (Eastman Kodak Co., Rochester, NY) was exposed overnight at $-70^{\circ} \mathrm{C}$.

Probe preparation. Plasmids used for probe preparation were a generous gift from E. Boncinnelli, and have been well-characterized by this group and others $(9,10)$. pGEM plasmids containing 103 base pairs of the $3^{\prime}$ untranslated region of human $H O X A 10$ were linearized with Eco RI or Hind III (New England Biolabs Inc., Beverly, MA), ethanol-precipitated, and used as template for generating riboprobes. Radiolabeled RNA probes were generated by in vitro transcription using the Riboprobe kit (Promega Corp., Madison, WI). Sense and antisense probes were generated using the appropriate 
RNA polymerase (T7 or SP6) and labeled with $\alpha\left[{ }^{33} \mathrm{P}\right]$ or $\left[{ }^{32} \mathrm{P}\right] \mathrm{UTP}$ (Amersham, Arlington Heights, IL).

In situ hybridization. In situ hybridization was performed with both sense and antisense ${ }^{33} \mathrm{P}$-labeled riboprobes. Endometrium was fixed in $4 \%$ paraformaldehyde, cryoprotected in 30\% sucrose, and then embedded in OCT compound (Miles Laboratories, Elkhart, IN). $10-\mu \mathrm{m}$ frozen sections were obtained and mounted on Vectabondcoated slides (Vector Laboratories, Inc., Burlingame, CA). Before use, sections were treated with $0.2 \mathrm{M} \mathrm{HCl}$, Pronase $(0.16 \mathrm{mg} / \mathrm{ml})$, and $0.026 \mathrm{M}$ acetic anhydride, and were then dehydrated. Tissue sections were hybridized overnight with $3 \times 10^{6} \mathrm{cpm}$ of each probe in $0.25 \mathrm{M}$ $\mathrm{NaCl}, 0.01 \mathrm{M}$ Tris- $\mathrm{HCl}$ (pH 7.5), $0.01 \mathrm{M} \mathrm{NaPO} 4$ (pH 6.8), $5 \mathrm{mM}$ EDTA, Ficoll $400(0.02 \%)$, polyvinylpyrolidone (0.02\%), BSA Fraction $\mathrm{V}(0.02 \%), 50 \%$ formamide, $12.5 \%$ dextran sulfate, yeast tRNA $(1.25 \mathrm{mg} / \mathrm{ml})$, and $10 \mathrm{mM}$ DTT. Hybridization was performed in a humidified chamber for $16 \mathrm{~h}$ at $50^{\circ} \mathrm{C}$. Slides were treated with RNase A at $37^{\circ} \mathrm{C}$, and were then washed for $16 \mathrm{~h}$ in $0.25 \mathrm{M} \mathrm{NaCl}, 0.01 \mathrm{M}$ Tris$\mathrm{Cl}$ (pH 7.5), $0.01 \mathrm{M}$ sodium phosphate ( $\mathrm{pH}$ 6.8), 5 mM EDTA, Ficoll $400(0.02 \%)$, polyvinylpyrolidone $(0.02 \%)$, BSA Fraction V $(0.02 \%)$, and $50 \%$ formamide. Slides were dehydrated, dried, and dipped in K5D (Ilford Limited, Mobberley, Cheshire, United Kingdom) emulsion. Exposure was carried out at $4^{\circ} \mathrm{C}$ for 7-12 d, and slides were developed with Kodak D-19 (Eastman Kodak Co.). Slides were counterstained with hematoxylin and eosin. Representative darkfield and bright-field photomicrographs were taken at $20 \times$ on a microscope (Olympus Corp., Lake Success, NY) with Kodak Ektachrome film (Eastman Kodak Co.).

Cell culture. Endometrial samples were obtained from four different normal cycling women in the proliferative phase. Endometrial epithelium and stromal cells were separated as described previously (11). In brief, the tissue was finely minced, and cells were dispersed by incubation in HBSS containing Hepes $(25 \mathrm{mM})$, penicillin $(200 \mathrm{U} / \mathrm{ml})$, streptomycin $(200 \mu \mathrm{g} / \mathrm{ml})$, collagenase $(1 \mathrm{mg} / \mathrm{ml}, 15 \mathrm{U} / \mathrm{mg})$, and DNase $(0.1 \mathrm{mg} / \mathrm{ml}, 1,500 \mathrm{U} / \mathrm{mg})$ for $20-30 \mathrm{~min}$ at $37^{\circ} \mathrm{C}$ with agitation. The cells were separated by filtration through a wire sieve with $73-\mu \mathrm{g}$ diameter pores. The stromal cells are found in the filtrate, whereas the endometrial glands are retained by the sieve. The stromal cells were pelleted, washed, and suspended in phenol red-free Ham's F12/ DME (1:1) containing antibiotics and 10\% charcoal-stripped FCS. The cells were passaged once and grown to confluence. Confluent monolayers were maintained in serum-free media for $48 \mathrm{~h}$, and subsequently treated with $17 \beta$ estradiol $\left(5 \times 10^{-8} \mathrm{M}\right)$ or medroxyprogesterone acetate $\left(1 \times 10^{-7} \mathrm{M}\right)$. Immunocytochemical analysis of endometrial cells was conducted after the first passage. Factor VIII, cytokeratin, $3 \mathrm{C} 10$, and vimentin were used as markers of endothelial cells, epithelial cells, macrophages and stromal cells, respectively. $97 \%$ of the cells were endometrial stromal cells. Epithelial cells and macrophages accounted for $\sim 3 \%$ and $0.2 \%$ of the cells; endothelial cells were absent. Estrogen and progesterone receptor status was verified by ELISA according to the manufacturer's instructions (Abbot Laboratories, Weisbaden, Germany). Ishikawa cells were grown in the same medium and treated identically to the primary stromal cells.

Statistical analysis. The autoradiographic bands were quantified using a laser densitometer (Molecular Dynamics, Sunnyvale, CA). Each $H O X A 10$ band was normalized to the value obtained from the same lane hybridized to G3PDH. Data were analyzed using ANOVA. Statistical significance was defined as $P<0.05$.

\section{Results}

Endometrial HOXA10 expression is menstrual cycle stagedependent. To examine the role of HOXA10 in the cyclic development of the endometrium, the menstrual cycle stage-specific expression pattern was determined. Total RNA was extracted from human endometrium collected from normal cycling women. The 30 specimens were divided into approximately equal groups corresponding to early and late prolifer-



b

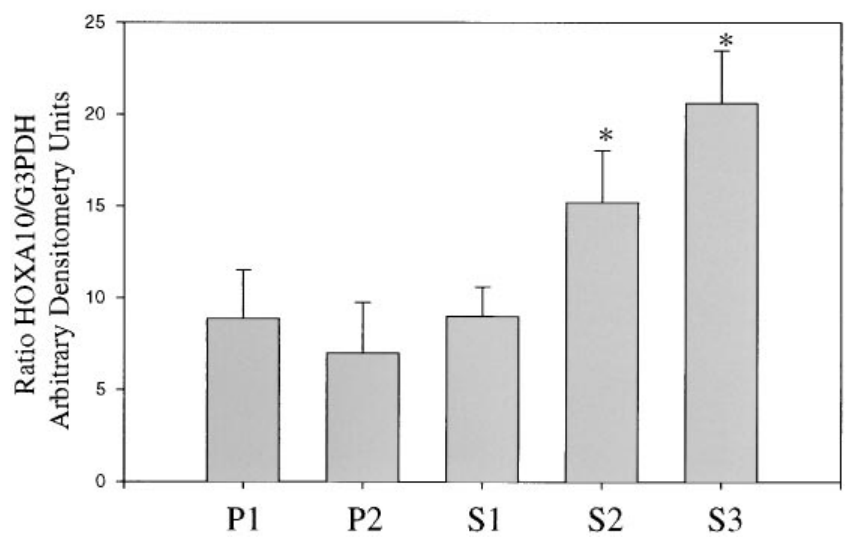

Figure 1. (a) Northern blot analysis of HOXA10 expression in endometrium during the menstrual cycle. A representative autoradiogram is shown after exposure for $24 \mathrm{~h}$. HOXA10 is expressed in the first half of the proliferative phase $(P 1)$, the second half of the proliferative phase $(P 2)$, and the first third of the secretory phase $(S 1)$. A dramatic increase in expression occurs in the mid secretory phase $(S 2)$ corresponding to the time of implantation, and persists into the late secretory phase $(S 3)$. Northern blot hybridized with a probe to glyceraldehyde-3-phosphate dehydrogenase (G3PDH; bottom). (b) Densitometric analysis of $H O X A 10$ expression in 30 endometrial samples normalized to G3PDH. There is no statistical difference within the proliferative phase or between the proliferative phase and the early secretory phase. *Statistically significant increase in HOXA10 expression in the midsecretory phase of the menstrual cycle compared with the proliferative phase. There is no statistical difference between expression in the mid and late secretory phases. Error bars are SEM.

ative stage, and to early, mid, and late secretory stage endometrium. An additional sample of pregnancy decidua was also examined. Northern blot analysis was performed using an antisense ${ }^{32} \mathrm{P}$-labeled riboprobe specific to the $3^{\prime}$ untranslated region of $H O X A 10$. Representative results are shown in Fig. 1 a. Expression is evident throughout the menstrual cycle, but increases in the midsecretory phase. Hybridization to a control 
a



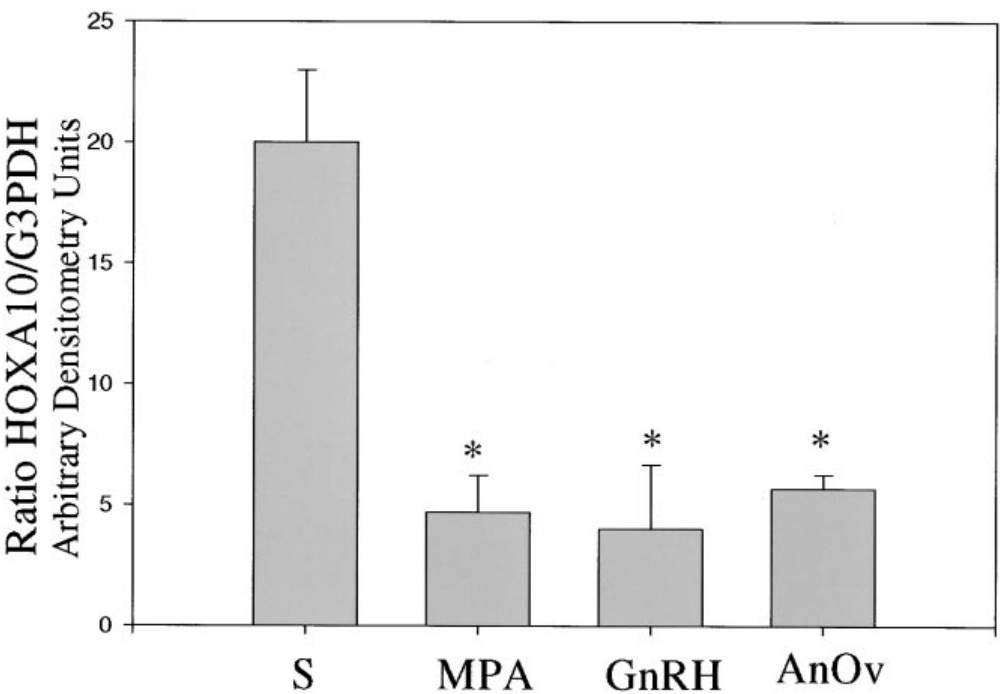

Figure 2. (a) Northern blot analysis of HOXA10 expression in endometrium from the late secretory phase of the menstrual cycle $(S)$ and the decidualized endometrium of pregnancy $(D)$. A representative autoradiogram is shown after exposure for $24 \mathrm{~h}$. HOXA10 expression persists into pregnancy. (b) Expression of $H O X A 10$ is altered in nonreceptive endometrium. Northern analysis was performed on endometrial samples from three women in the late secretory phase $(S)$ and three women with each of the following conditions: long-term treatment with medroxyprogesterone acetate $(M P A)$, treatment with gonadotropin-releasing hormone analog $(G n R H)$, and chronic anovulation $(A n O v)$. Densitometric analysis normalized to G3PDH is shown. Error bars are SEM. *Statistically different from secretory endometrium.

probe $(\mathrm{G} 3 \mathrm{PDH})$ shows that approximately equal amounts of RNA were loaded into each lane. Densitometric analysis was performed on each sample, and Fig. $1 b$ shows the average abundance of $H O X A 10$ during each stage of the menstrual cycle normalized to G3PDH. There was no statistical difference between the levels of expression in any of the segments of the proliferative phase or the early secretory phase. In contrast, expression at the mid and late secretory phase was significantly elevated relative to earlier stages. Expression in the mid and late secretory phase was not significantly different. Taken together, these results indicate that $H O X A 10$ expression varies during the menstrual cycle, and markedly increases at the midsecretory phase, which corresponds to the time of implantation. Additionally, $H O X A 10$ expression persists in the decidua of pregnancy as demonstrated in Fig. $2 a$.

$H O X A 10$ is expressed at low levels in the endometrium of women with pharmacologically modified or pathologic states of altered endometrial development that lack receptivity to implantation. Fig. $2 b$ shows that $H O X A 10$ levels are significantly lower in the endometrium of patients treated with longterm medroxyprogesterone acetate or gonadotropin-releasing hormone agonist, in comparison with levels of HOXA10 in secretory endometrium. Additionally, endometrium from patients with chronic anovulation shows low $H O X A 10$ expression.

HOXA10 is expressed in both the endometrial stroma and glands. HOXA10 expression was localized within the endometrium using in situ hybridization. Tissue sections were obtained from endometrium spanning the menstrual cycle, and in situ hybridization was performed using a ${ }^{33} \mathrm{P}$-labeled antisense riboprobe containing the $3^{\prime}$ untranslated region of $H O X A 10$. Fig. 3, $a$ and $b$ show brightfield and darkfield illumination, respectively, of representative sections of secretory en- dometrium. Expression is noted in both glandular and stromal cells. Fig. $3 c$ shows a high-power brightfield view of $H O X A 10$ expression in proliferative endometrium as demonstrated by in situ hybridization. $H O X A 10$ is expressed in both glandular and stromal cells. Levels of expression appeared higher in the mid and late secretory phase, confirming the results of the Northern blot analysis (not shown).

HOXA10 expression is modulated by sex steroids in endometrial cell culture. The increased HOXA10 expression observed in the midsecretory endometrium coincided with the time of increased circulating progesterone. To test whether $H O X A 10$ expression is regulated by sex steroids, $H O X A 10$ expression was measured in cultured cells after treatment with estrogen and progesterone. Endometrial samples from the proliferative phase of the menstrual cycle were used as a source of primary cultures of stromal cells. Cells were grown to confluence in steroid-free media, and were serum-starved before treatment with physiologic concentrations of 17-beta estradiol, medroxyprogesterone acetate, or both. RNA was extracted and subjected to Northern blot analysis. Fig. $4 a$ shows that estrogen stimulated $H O X A 10$ expression approximately twofold compared with control cells that were not exposed to steroids. Treatment with progesterone stimulated $\mathrm{HOXA10}$ expression to a greater degree than did estrogen alone. Combined treatment with estrogen and progesterone was additive. Average densitometry readings are displayed in Fig. $4 \mathrm{~b}$, confirming the response to sex steroids in independent cell lines. These cells show similar $H O X A 10$ expression after exposure to concentrations of estrogen beyond physiologic ranges $\left(10^{-10}-10^{-6} \mathrm{M}\right)$. A dose responsive expression over the physiologic range of progesterone concentration is displayed in Fig. 5. These findings are consistent with the observed increased expression of $H O X A 10$ in the endometrium of the secretory 


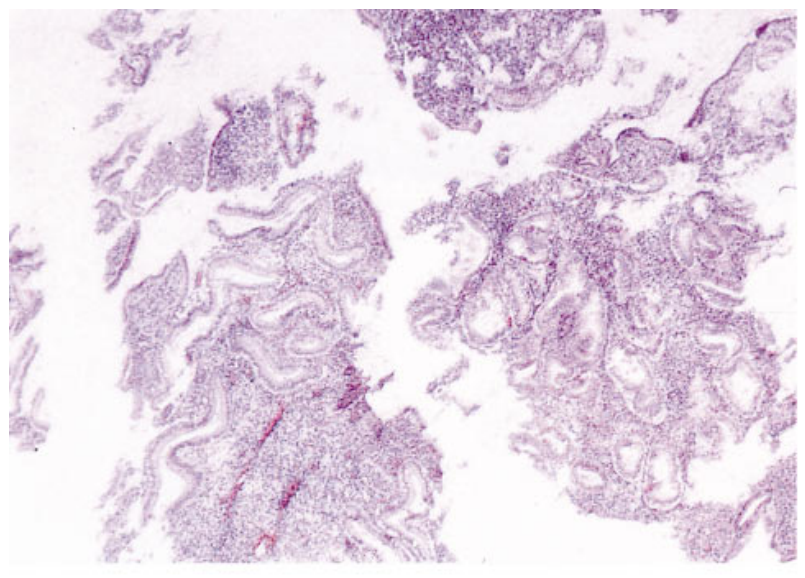

a

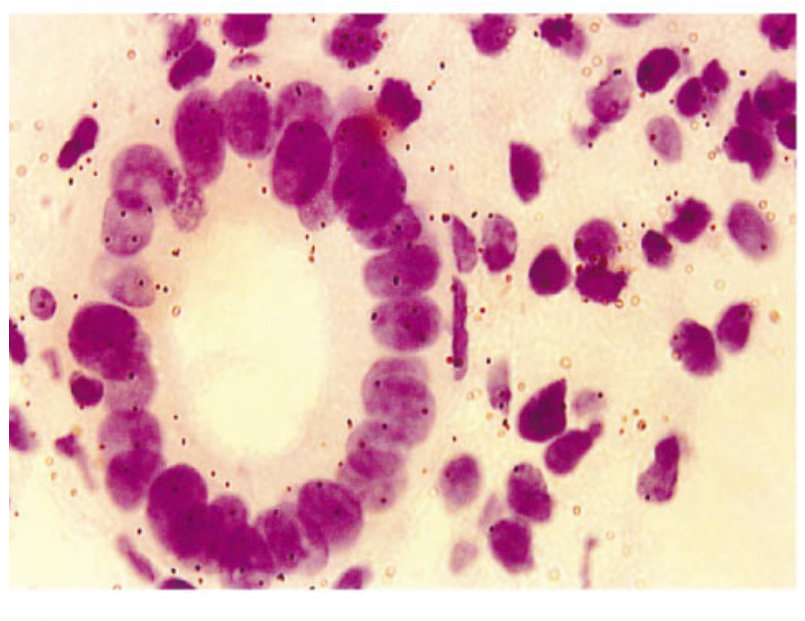

$\mathrm{C}$

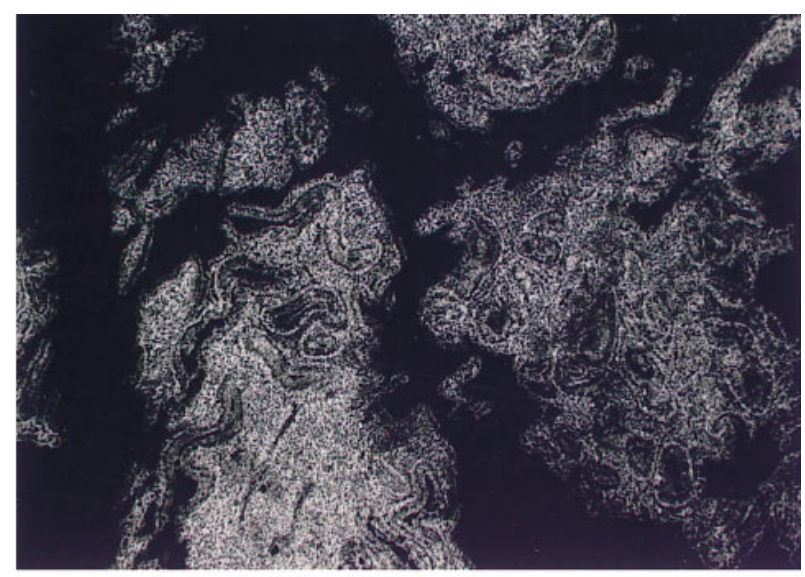

b

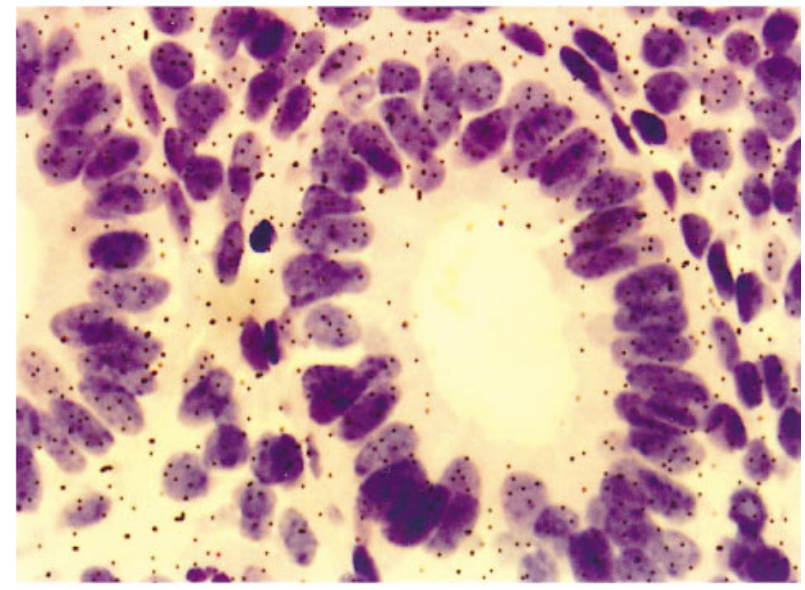

d

Figure 3. (a) Brightfield illumination of secretory endometrium stained with hematoxylin and eosin. (b) Darkfield illumination after in situ hybridization with an $H O X A 10$ antisense riboprobe. Both glandular and stromal components show $H O X A 10$ expression. Hybridization with a sense riboprobe showed no significant signal (not shown). 20×. (c) A high-power brightfield illumination after in situ hybridization demonstrates $H O X A 10$ expression in both the glands and stroma of proliferative-phase endometrium and $(d)$ secretory phase endometrium.

phase of the menstrual cycle when estrogen is present and progesterone is increased.

To verify that sex steroids stimulate HOXA10 expression, studies were performed using Ishikawa cells, a well-differentiated endometrial adenocarcinoma cell line derived from the glandular component of the endometrium $(12,13)$. The presence of estrogen and progesterone receptor was documented by ELISA (not shown). Ishikawa cells were cultured under similar conditions as stromal cells, and treated with the same concentrations of sex steroids. Fig. 6 shows that Ishikawa cells express $H O X A 10$, and that expression increases approximately twofold after treatment with either estrogen or progesterone. In contrast to stromal cells, the effects of estrogen and progesterone are not additive. To assure that the progesterone effect on HOXA10 expression is mediated through the progesterone receptor in Ishikawa cells, the cells were pretreated with the antiprogesterone RU486. RU486 blocked the response to progesterone. These results confirm a regulatory role for sex steroids on HOXA10 expression. In Ishikawa cells, maximal levels of $H O X A 10$ mRNA were reached within $1 \mathrm{~h}$ of exposure to estrogen or progesterone, and remained elevated at $8 \mathrm{~h}$ (not shown). Treatment with cycloheximide before adding steroid hormones had no effect on the increase in HOXA10 expression, suggesting that new protein synthesis was not required (Fig. 7).

\section{Discussion}

One way in which differential tissue identity is obtained is through selective activation of $H O X$ genes. The role of $H O X$ genes in differentiation of embryonic tissues is well-established. We have recently described the role of $H O X$ genes of the A axis in mullerian system development, and their persistent expression in the adult female reproductive system (7). HOXA10 is expressed in the glands and stroma of the adult endometrium.

Endometrial glands and stroma undergo cyclic developmental changes in response to circulating sex steroids. We 
a

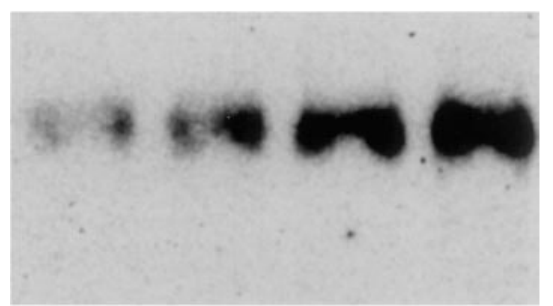

HOXA10

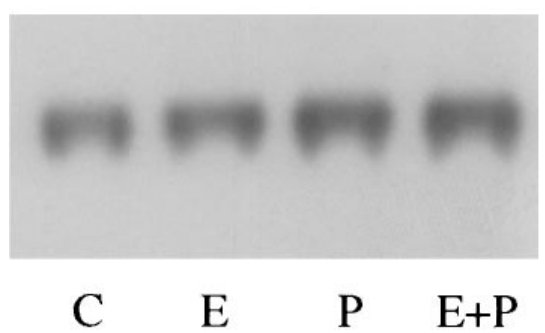

G3PDH

b

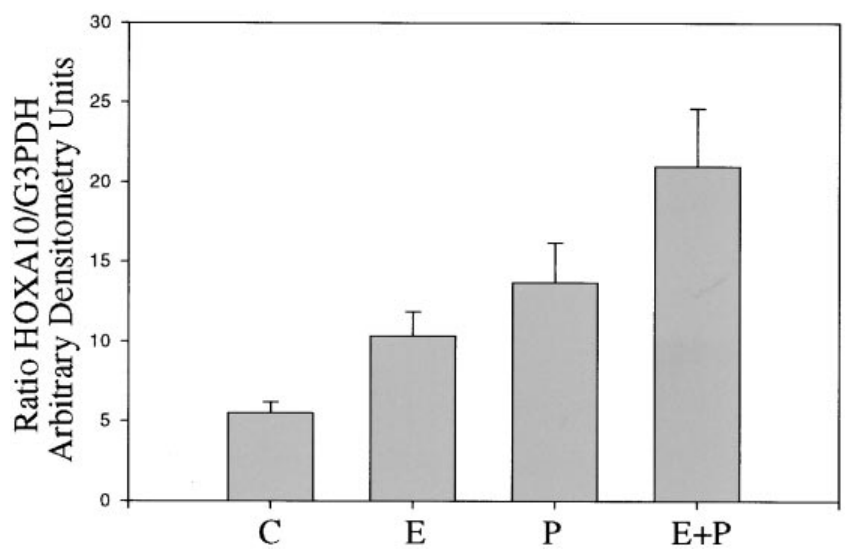

Figure 4. (a) Northern blot analysis of HOXA10 expression in cultured primary endometrial stromal cells. RNA from control cells $(C)$ that were not exposed to steroid shows basal levels of $H O X A 10$ expression. Cells were treated with $5 \times 10^{-8} \mathrm{M}$ estrogen $(E), 1 \times 10^{-7} \mathrm{M}$ progesterone $(P)$, or both hormones for $4 \mathrm{~h}$. HOXA10 expression increased with estrogen or progesterone. The effects of estrogen and progesterone were additive. A representative autoradiogram is shown. (b) Densitometric analysis of HOXA10 expression from four stromal cell cultures obtained from different patients. Data were normalized to G3PDH. A statistically significant difference was observed between each lane. Error bars are SEM.

demonstrate that $H O X A 10$ is expressed in the endometrium in a menstrual cycle stage-dependent fashion. HOXA10 expression is noted in the proliferative phase of the menstrual cycle when estrogen is the predominant steroid hormone affecting the uterus. HOXA10 mRNA levels dramatically increase in the midsecretory phase at the time when progesterone levels rise rapidly. A parallel increase in expression is noted in cell culture experiments in which both primary stromal cells and Ishikawa endometrial adenocarcinoma cells increase HOXA10 expression in response to estrogen and progesterone. It is possible that differential HOXA10 expression in response to changing estrogen and progesterone concentrations

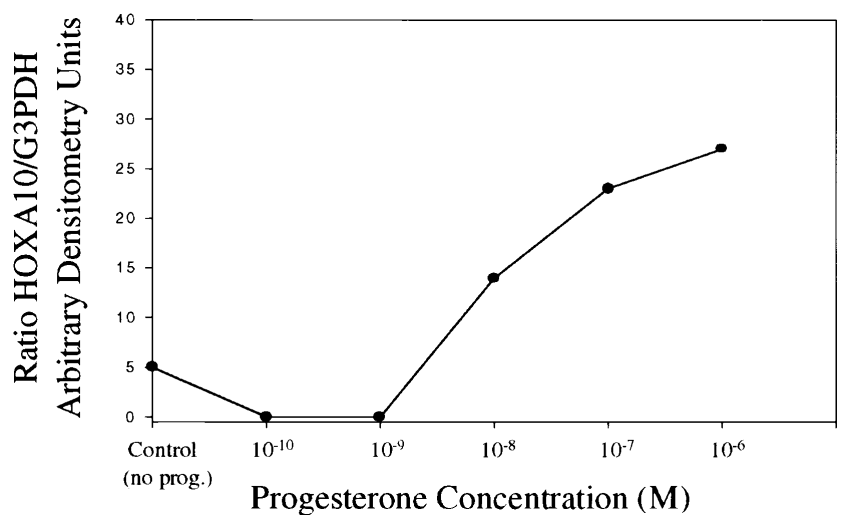

Figure 5. Dose response of $H O X A 10$ expression after treatment with progesterone. Primary stromal cells were treated with varying concentrations of progesterone, and Northern blot analysis was performed. HOXA10 expression relative to G3PDH control is shown. An increase in HOXA10 expression was noted over the physiologic range.

leads to sequential differentiation of the endometrium. $H O X$ genes may play a role in the menstrual cycle, altering cell fate during differentiation of the endometrium.

During vertebrate development, morphogens convey positional information and selectively alter the expression of essential regulatory genes. Previously, $H O X$ genes have been shown to be regulated by the morphogen retinoic acid $(14,15)$. The retinoic acid receptor belongs to the family of nuclear hormone receptors that includes the estrogen and progesterone receptors. Here we show that $H O X A 10$ expression is modulated by other nuclear hormone receptor ligands, estrogen, and progesterone, presumably acting through their respective receptors. Growth and differentiation of the uterine endo-

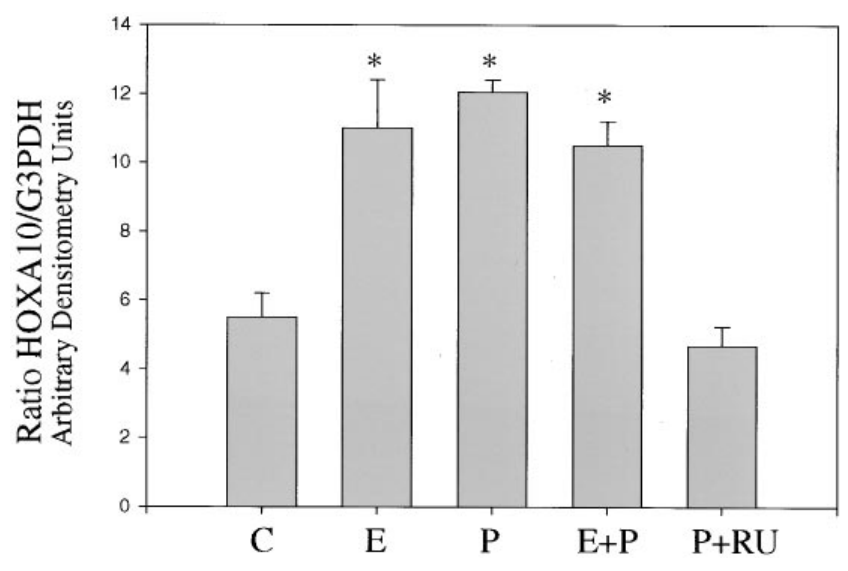

Figure 6. Expression of $H O X A 10$ in Ishikawa cells in response to sex steroids. Cells that were demonstrated to be estrogen- and progesterone receptor-positive showed $H O X A 10$ expression in the untreated state $(C)$. Treatment with $5 \times 10^{-8} \mathrm{M}$ estrogen $(E), 1 \times 10^{-7} \mathrm{M}$ progesterone $(P)$, or both hormones $(E+P)$ resulted in similar stimulation of $H O X A 10$ expression. The progesterone-induced expression is blocked by $1 \times 10^{-6} \mathrm{M}$ RU486 $(P+R U)$. Average densitometry results normalized to G3PDH are shown. Error bars are SEM. *Statistically different from control. 


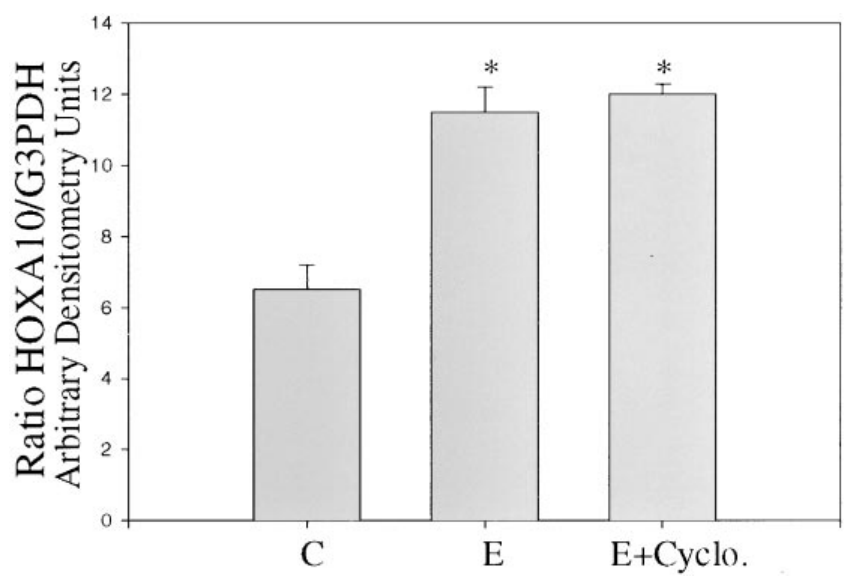

Figure 7. Expression of $H O X A 10$ in Ishikawa cells is not altered by cycloheximide treatment. Cells were treated with cycloheximide before steroid administration. Northern blot analysis and densitometry results show that $H O X A 10$ expression was inducible with estrogen (E) after cycloheximide pretreatment. Error bars are SEM. *Statistically different from control.

metrium during the menstrual cycle and pregnancy is governed principally by progressive changes in the levels of sex steroids. As $H O X$ genes respond to the morphogen retinoic acid during embryonic development, they may respond to sex steroids in the developing adult uterine endometrium.

Estrogen and progesterone are novel regulators of $\mathrm{HOX}$ gene expression. Besides retinoic acid, few regulatory molecules inducing $H O X$ expression are known. The rapid induction of $H O X A 10$ expression in response to sex steroids as well as the lack of inhibition by cycloheximide suggest that steroid hormones and their receptors likely bind directly to regulatory elements of $H O X A 10$. This is the first demonstration of a steroid hormone acting as a direct regulator of $H O X$ expression. It will be interesting to determine if other $H O X$ genes respond to these steroids.

Targeted disruption of the Hoxal0 gene in the mouse results in an infertility phenotype (6). Females lacking Hoxa10 have a uterine factor defect that results in death of the preimplantation embryo and failure of implantation. Homozygous mutants ovulate normally, and produce oocytes that can be fertilized with sperm from a wild-type male. When transferred to a surrogate wild-type uterus, these embryos develop normally, but wild-type embryos fail to implant in the Hoxa10 mutant uterus.

The location and timing of expression in the uterus is consistent with $H O X A 10$ playing a similar role in humans. $H O X A 10$ is differentially expressed in the uterine endometrium during the menstrual cycle. A dramatic increase in levels of expression accompanies endometrial differentiation at the midsecretory phase, which is the time of implantation in the human. A striking conservation of gene function between species is commonly observed (16). The homeobox of the murine Hoxa10 gene is $95 \%$ conserved with the human HOXA10 gene at the nucleotide level, and $100 \%$ conserved at the amino acid level (17). Most genes that are known to be expressed in the secretory phase endometrium do not have a necessary role in implantation; targeted mutations have typically failed to demonstrate an effect on the ability of the uterus to support an embryo. In contrast, Hoxa10 is essential for implantation in the mouse. Functional conservation between species implies that these two genes (human HOXA10 and murine Hoxa10) with highly conserved sequences have a similar role in both species. The timing and location of expression in the human secretory endometrium further supports an essential function in human implantation. Furthermore, the persistent expression in decidua suggests a continued role in pregnancy maintenance.

\section{Acknowledgments}

This study was supported by a grant from the National Institutes of Child Health and Human Development to H. Taylor.

\section{References}

1. Krumlauf, R. 1994. Hox genes in vertebrate development. Cell. 78:191-201.

2. McGinnis, W., and R. Krumlauf. 1992. Homeobox genes and axial patterning. Cell. 68:283-302.

3. Duboule, D., and P. Dolle. 1989. The structure and functional organization of the murine Hox gene family resembles that of Drosophila homeotic genes. EMBO J. 8:1497-1505.

4. Izpisua-Belmonte, J., H. Falkenstein, P. Dolle, A. Renucci, and D. Duboule. 1991. Murine genes related to the Drosophila AbdB homeotic gene are sequentially expressed during development of the posterior part of the body. EMBO J. 10:2279-2289.

5. Dolle, P., J. Izpisua-Belmonte, C. Ticlele, and D. Duboule. 1991. Hox-4 genes and the morphogenesis of mammalian genitalia. Genes Dev. 5:1767-1776.

6. Satokata, I., G. Benson, and R. Maas. 1995. Sexually dimorphic sterility phenotypes in Hoxa-10 deficient mice. Nature. 374:460-463.

7. Taylor, H., G. VandenHuvel, and P. Igarashi. 1997. A conserved hox axis in the mouse and human reproductive system; late establishment and persistent expression of the hoxa cluster genes. Biol. Reprod. 57:1338-1345.

8. Noyes, R.W., A.T. Hertig, and J. Rock. 1955. Dating the endometrial biopsy. Fertil. Steril. 1:3-25.

9. Shen, W., C. Largeman, P. Lowney, J. Corral, K. Detmer, C. Hauser, T. Simonitch, F. Hack, and H. Lawrence. 1989. Lineage-restricted expression of homeobox-containing genes in human hematopoietic cell lines. Proc. Natl. Acad. Sci. USA. 86:8536-8540.

10. Magli, M., P. Barba, A. Celetti, G. DeVita, C. Cillo, and E. Boncinelli. 1991. Coordinate regulation of HOX genes in human hematopoietic cells. Proc. Natl. Acad. Sci. USA. 88:6348-6352.

11. Casey, M.L., J. Smith, K. Nagai, L. Hersh, and P. MacDonald. 1994. Progesterone-regulated cyclic modulation of membrane metalloendopeptidase (enkephalinase) in human endometrium. J. Biol. Chem. 266:23041-23047.

12. Holinka, C., H. Hata, H. Kuramoto, and E. Gurpide. 1986. Effects of steroid hormones and antisteroids on alkaline phosphatase activity in human endometrial cancer cells (Ishikawa line). Cancer Res. 46:2771-2774.

13. Lessey, B., A. Ilesanmi, A. Castelbaum, L. Yaun, S. Somkuti, P. Satyaswaroop, and K. Chwalisz. 1996. Characterization of the functional progesterone receptor in an endometrial adenocarcinoma cell line (Ishikawa): progesterone-induced expression of the alpha1 integrin. J. Steroid Biochem. Molec. Biol. 59:31-39.

14. Simeone, A., D. Acampora, V. Nigro, A. Faiella, M. D’Esposito, A. Stornaiuolo, F. Mavilio, and E. Boncinelli. 1991. Differential regulation by retinoic acid of the homeobox genes of the four HOX loci in human embryonal carcinoma cells. Mech. Dev. 33: 215-228.

15. Stornaiuolo, A., D. Acampora, M. Pannese, M. D'Esposito, F. Morelli, E. Migliaccio, M. Rambaldi, A. Faiella, V. Nigro, A. Simeone, and E. Boncinelli. 1990. Human HOX genes are differentially activated by retinoic acid in embryonal carcinoma cells according to their position within the four loci. Cell Differ. Dev. 31:119-127.

16. Quiring, R., V. Walldorf, V. Koter, and W. Gehring. 1994. Homology of the eyeless gene of Drosophila to the small eye gene in mice and aniridia in humans. Science. 265:785-789.

17. Benson, G., T. Nguyen, and R. Mass. 1995. The expression pattern of the murine Hoxa-10 gene and the sequence recognition of its homeodomain reveal specific properties of abdominal B-like genes. Mol. Cell. Biol. 15: 15911601. 